\title{
The Philosophical Foundations of Informational Ecology ${ }^{\dagger}$
}

\author{
Tianen Wang ${ }^{1, *}$ and Jinyun Wang ${ }^{2}$ \\ 1 Division of Social Sciences, Shanghai University, Shanghai, China \\ 2 College of Liberal Arts, Shanghai University, No. 99 Shangda Road, Shanghai, China; \\ jingyunw1960@163.com \\ * Correspondence: tianen@shu.edu.cn \\ + Presented at the IS4SI 2017 Summit DIGITALISATION FOR A SUSTAINABLE SOCIETY, Gothenburg, \\ Sweden, 12-16 June 2017.
}

Published: 9 June 2017

Information ecology is a concept relative to intelligent agents. It's not about the ecology of information itself, but the ecological system that the intelligent agents exist as an informational way and process, produce, create information.

The information ecology consists of four levels: the level of information network is the basic level of matter and energy of information ecology; the level of information flow is the information processing level of information ecology; the level of information production is the evolution level of information ecology; and the level of information creation is the dynamic level of information ecology. Reciprocity is the radical characteristic of information ecology as well as information. The basic characteristic of natural ecology is physical; the basic characteristic of social ecology is relational; and the basic characteristic of information ecology is reciprocitical. The basic principle of information ecology development in human society is the interaction between information symmetry and asymmetry. The basic difference between information ecology and natural ecology is that the natural ecology is naturally formed, and the information ecology is basically intelligent agent-made. In the era of information civilization, information ecology is not only based on the natural ecology and social ecology, but also plays more and more important roles in natural ecology, especially in social ecology. The key to natural ecology is the natural balance; the key to social ecology is social harmony; and the key to information ecology is mutual arousing in the process of information based on information circulation.

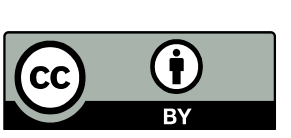

(C) 2017 by the authors. Licensee MDPI, Basel, Switzerland. This article is an open access article distributed under the terms and conditions of the Creative Commons Attribution (CC BY) license (http://creativecommons.org/licenses/by/4.0/). 